\title{
No limiar da persuasão: o movimento argumentativo na escrita de artigos de opinião por estudantes brasileiros
}

Ana Luiza Marcondes Garcia*

Egon de Oliveira Rangel ${ }^{\star *}$

* Departamento de

Linguística, Pontifícia Universidade Católica de São Paulo (PUC - SP)

** Departamento de Linguística, Pontifícia Universidade Católica de São Paulo (PUC - SP)

Este artigo integra o dossiê A produção de textos na Olimpíada de Língua Portuguesa. Em consequência, pressupõe o conhecimento dos pressupostos teóricos e metodológicos da própria Olimpíada, tais como caracterizados na "Introdução" ao dossiê. A análise incidiu sobre 383 textos produzidos por alunos do segundo e do terceiro ano do Ensino Médio público como artigos de opinião; e tomou como objeto de análise as estratégias e mecanismos de argumentação neles desenvolvidos.

\section{Resumo}

Este artigo apresenta parte dos resultados de uma pesquisa relativa a 383 textos, produzidos por estudantes de escolas públicas do segundo e terceiro anos do Ensino Médio, no contexto da Olimpíada 2010, como artigos de opinião. Apoiada numa concepção de argumentação tanto discursiva (PERELMAN, 1987) quanto estrutural ou anatômica (TOULMIN, 2001; RIEKE; SILLARS, 1975) e tomando como objeto a amostra já referida, a investigação buscou apreender de que forma as estratégias e os mecanismos argumentativos são postos em funcionamento nos textos, do ponto de vista discursivo, textual e linguístico-gramatical. A dificuldade em reconstruir as características do auditório para representar os destinatários do discurso, decorrente também das complexas condições de produção do texto, aparece como determinante para explicar o grande número de exemplares da amostra que não chegam a configurar-se como artigos de opinião típicos.

PALAVRAS-ChAVE: Estratégias argumentativas. Produção de textos escritos. Artigo de opinião. 


\section{ARTIGO DE OPINIÃO: UM GÊNERO DE VOCAÇÃO REPUBLICANA}

Dentre os gêneros propostos aos estudantes pela Olimpíada, certamente o artigo de opinião é aquele que, por sua própria natureza e função, mais favorece a participação do aluno-autor na vida pública e na construção da cidadania. Trata-se de produzir textos com o olhar voltado a temas de interesse coletivo, que dizem respeito a todos, a problemas que demandam soluções mais ou menos consensuais, decisões a serem tomadas, rumos a serem seguidos, valores a serem examinados. Discussões, enfim, cujo encaminhamento pode, direta ou indiretamente, afetar a vida de toda uma população (CENPEC, 2010).

É justamente pela via de acentuar a necessidade e a importância de debater temas dessa natureza, como forma de participar da vida em sociedade e exercitar a cidadania, que se realizou o convite aos estudantes de segundo e terceiro anos do Ensino Médio para que concorressem na Olimpíada escrevendo um artigo de opinião.

Como detalhado na Apresentação deste dossiê, tal convite foi realizado indiretamente, por meio da publicação Pontos de vista: caderno do professor (CENPEC, 2010), que orienta a organização do trabalho docente. Tal título já adianta, tanto para professores quanto para estudantes, que o movimento principal a ser executado na produção desse gênero é de identificar e formular questões polêmicas que atravessam o nosso cotidiano, com a intenção de assumir uma posição própria em relação a elas, sustentando-se em razões. Na base, portanto, desse movimento, está a capacidade de argumentar, a habilidade em convencer o leitor de que um certo ponto de vista justifica-se em função dos fatos considerados, das provas apresentadas, do raciocínio efetuado, ou seja, dos argumentos arrolados.

Por esse motivo é que se elegeu a argumentação como fio condutor para o presente artigo, cujo objetivo principal será, então, examinar com base na amostra já referida como se processou, na Olimpíada 2010, o movimento argumentativo nos textos produzidos pelos estudantes brasileiros.

Para tanto buscaremos, primeiro, caracterizar a concepção de argumentação que deu sustentação teórica às atividades propostas no caderno do professor, previstas para um período de três a quatro meses, e que deram origem às produções discentes. Tais atividades compreenderam tanto a realização das 15 oficinas sistematizadas no caderno do professor quanto a utilização do jogo QP Brasil, que complementa as oficinas. 
Em seguida, considerando o quadro teórico explicitado, passaremos à análise propriamente dita dos textos, focalizando, em alguns deles, como se processou ali a argumentação, em que medida foi bem ou malsucedida no texto como um todo e em que passagens poderia ter sido conduzida de forma mais eficaz para garantir a adesão do leitor. Esse exame incidirá sobre três aspectos distintos dos textos - discursivo, textual e linguístico-gramatical - e permitirá o estabelecimento de sugestões sobre fases ou processos envolvidos na produção de textos argumentativos em que valerá a pena o professor insistir, nas próximas edições do certame, para que os estudantes compreendam melhor e utilizem com maior eficácia as estratégias e os mecanismos argumentativos que um artigo de opinião pode envolver.

\section{ARGUMENTAÇÃO: MARCOS TEÓRICOS}

Três trabalhos, hoje já clássicos, fornecem as principais referências teóricas para a proposição das atividades que, no caderno Pontos de vista, precedem a escrita da versão final do artigo de opinião, na Olimpíada. Em consequência também se constituem como marcos teóricos de nossas análises neste artigo.

Dois deles, do filósofo belga Chaïm Perelman e do lógico britânico Stephen Toulmin, respectivamente o Tratado da argumentação: a nova retórica e Os usos do argumento, foram publicados no mesmo ano de 1958. Ambos buscavam revalorizar o que se denomina de Retórica Antiga, inserindo-a no quadro mais geral de uma Teoria da Argumentação e buscando evitar a perda de prestígio que aquela havia sofrido ao ser entendida como sedução, ou seja, uma prática de manipulação das ideias pelo uso de sofismas e artifícios estilísticos que, enganando o entendimento, visam convencer pela emoção. Por outro lado, nos dois autores referidos, a argumentação, por sua natureza retórica, tampouco se confunde com a demonstração lógico-matemática, situando-se antes no terreno da probabilidade e do plausível.

Assim, a nova retórica deve ser concebida, para Perelman (2000), como uma maneira de debater, em fóruns socialmente constituídos, um acordo sobre valores, sem abandonar o campo da razão mas, ao mesmo tempo, transcendendo as categorias da demonstração. Tal empreendimento justifica-se pelo fato de que esta última, por visar o mero estabelecimento de relações lógicas entre premissas e conclusão, trabalha com provas impessoais, não se ocupando, portanto, da opinião; enquanto a argumentação é necessariamente pessoal, pois está voltada a indivíduos dos quais almeja obter a adesão, ainda que sob certas condições e em diferentes graus de intensidade (PERELMAN, 1987). 
Segundo este autor,

argumentar é fornecer argumentos, ou seja, razões, a favor ou contra uma determinada

tese. Uma teoria da argumentação, na sua acepção moderna, vem assim retomar e, ao mesmo tempo, renovar a retórica dos Gregos e dos Romanos, concebida como arte de bem falar, ou seja, a arte de falar de modo a persuadir e a convencer, e retoma a dialética e a tópica, artes do diálogo e da controvérsia (PERELMAN, 1987, p. 234).

Portanto, a ideia de redefinição da retórica, para esse autor, centra-se em primeiro lugar na compreensão da argumentação como um discurso; e, não menos importante, na consideração do conceito de auditório, definido como o conjunto daqueles a quem o orador se propõe a influenciar, ou seja, seus destinatários. Assim, Perelman promove interessante construção ao estabelecer "discurso", "auditório" e "orador" como elementos centrais da argumentação, entendida como método para provocar ou aumentar a adesão dos indivíduos às teses que lhes são apresentadas.

Assim, é particularmente importante para os propósitos do presente artigo ressaltar a ideia de que, nessa concepção, ao contrário do sistema lógico dedutivo que se estabelece independentemente de qualquer contexto, a argumentação apresenta-se como necessariamente situada, já que exige o contato entre sujeitos:

Querer persuadir um auditor significa, antes de mais nada, reconhecer-lhes as capacidades e as qualidades de um ser com o qual a comunicação é possivel e, em seguida, renunciar a dar-lhe ordens que exprimam uma simples relação de força, mas sim procurar ganhar a sua adesão intelectual. Não se pode persuadir um auditório senão tendo em conta as suas reações, de modo a adaptar o seu discurso a estas reações (PERELMAN, 1987, p. 235).

Ou seja, o auditório determina o modo de proceder do orador, já que este deve se adaptar às características daquele; nas palavras do autor, "a qualidade de um auditório determina a da argumentação" (PERELMAN, 1987, p. 237). Falhar nesse princípio provoca um dos erros mais comuns em uma argumentação: incorrer na "petição de princípio", que consiste em "supor admitida uma tese que se desejaria fazer admitir pelo auditório" (PERELMAN, 1987, p. 240).

Uma vez admitidos esses pressupostos, Perelman (1987) prossegue no exame dos diferentes tipos de auditórios, nas diferentes técnicas argumentativas e na natureza dos diversos argumentos, que não cabe detalhar aqui, dados os propósitos do presente artigo. Cabe, sim, observar que a abordagem que o autor propõe para o estudo e a prática da argumentação determina a concepção discursiva da argumentação presente nas oficinas propostas para a produção do artigo de opinião. Ao longo delas, busca-se trabalhar, na medida em que os objetivos e o fôlego desse material destinado ao professor 
permitem, a questão das estratégias argumentativas (CENPEC, 2010), sempre ressaltando-se a importância do reconhecimento do auditório para a definição de tais estratégias.

Uma vez caracterizado o auditório, faz-se necessário eleger argumentos, formulados de modo a se amoldar aos destinatários. Entretanto, a estrutura lógica do silogismo clássico - rigidamente composta de premissa maior, premissa menor e conclusão - não disporia da flexibilidade necessária para que esse esquema se alterasse em função do auditório.

É para dar conta desse aspecto específico que o lógico inglês Toulmin (2001), o nosso segundo autor, especifica, por meio de um modelo anatômico, os elementos potencialmente constitutivos de qualquer tipo de argumentação. Para tanto, Toulmin redefine e renomeia os três elementos básicos do silogismo clássico, explicitando as relações que ocorrem entre eles; e introduz três novos elementos que podem compor a argumentação, contemplando, assim, a necessidade de negociar posições, movimento típico do discurso argumentativo.

Segundo Toulmin (2001), a argumentação é o desenvolvimento de um raciocínio que parte de dados aceitos e que, por meio de uma justificativa, conduz o ouvinte a uma conclusão possível.

A Conclusão (C) é a ideia cujos méritos procura-se estabelecer, ou seja, a tese. Sempre de natureza controvertida, pode ser a proposição final da argumentação ou então uma afirmação intermediária que funcionará como Dado para outro argumento. Os dados (D) correspondem aos fatos geralmente tidos como evidentes - eventos, indícios, informações, asserções aceitas ou já comprovadas etc. -, essenciais no processo como um todo, já que se constituem no ponto de partida da argumentação. Já a Justificativa (J) é o elemento que permite realizar o salto mental capaz de superar a distância que há entre Dado e Conclusão; seu papel é o de conduzir os Dados já aceitos em direção à afirmação de natureza controvertida que é a Conclusão.

É importante perceber que enquanto os Dados fazem um apelo explícito ao ouvinte, a Justificativa, de natureza mais geral, pode apelar apenas implicitamente. Nesse caso, presume-se que a informação contida na Justificativa seja apenas inferida. Tais informações não explícitas é que, muitas vezes, estabelecem a coerência do texto.

Esses três elementos básicos - Dados, Justificativa e Conclusão - compõem o núcleo da argumentação; a eles o autor acresce outros três. 
Diferentes tipos de Justificativa vão conferir diferentes graus de força à Conclusão: enquanto uma Justificativa pode conduzir necessariamente a uma Conclusão, outra pode indicar apenas alta probabilidade. Esses graus de força podem ser expressos pelo que o autor denomina de Modalizadores (M), veiculados no texto por palavras ou expressões que indicam a atitude ou posição do orador perante suas próprias afirmações; é assim que certa asserção pode ser atenuada ou acentuada pelo uso de expressões (tais como provavelmente, possivelmente, talvez, sem sombra de dúvida, é certo que etc.), de verbos modais (como poder), de tempos verbais (como o condicional), etc. O quinto componente da argumentação busca dar conta da necessidade de um orador antecipar e contestar de antemão uma possível objeção a sua tese, ou mesmo de fazer referência a certas condições sob as quais a sua própria Conclusão poderia não ocorrer. Esse é o papel da Refutação (R), que trabalha com os prováveis contra-argumentos a serem, presumivelmente, utilizados pelos opositores da tese; ao antecipar e afastar posições contrárias, a refutação, na verdade, fortalece a tese; e, ao funcionar como uma espécie de válvula de escape para a Conclusão, protege o orador de eventuais objeções. Finalmente, pode ainda ocorrer o caso em que uma Justificativa não tenha suficiente força para garantir a Conclusão; é necessário, então, usar um Suporte (S) para complementar as informações e garantir maior peso à Justificativa, ou mesmo para os próprios Dados.

Estes seis componentes da argumentação poderiam ser expressos, esquematicamente, na figura a seguir, compondo uma espécie de esqueleto básico do argumento, em que as linhas pontilhadas, que ligam os Dados à Conclusão, marcam uma relação lógica indireta; marcam, portanto, uma relação não evidente, cuja possibilidade lógica precisa ser estabelecida ou demonstrada pela Justificativa. Já as linhas cheias indicam relações lógicas diretas e necessárias e ocorrem entre a Justificativa e os dois outros elementos que ela articula - Dados e Conclusão -, ou entre o Suporte e Justificativas, que aquele complementa e reforça, lembrando que o Suporte poderia também ser usado para reforçar os próprios Dados. 
D

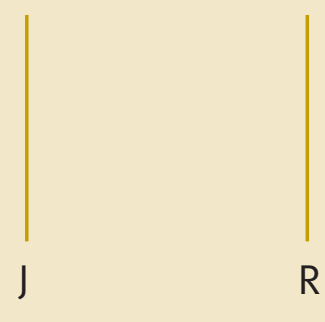

$\mathrm{R}$
M C

O Suporte está para a Justificativa assim como os Dados estão para a Conclusão; os Dados estão necessariamente explícitos, já que são o ponto de partida; o Suporte pode ser desnecessário, se a Justificativa se sustenta por si só.

Para Toulmin (2001), essas distinções são importantes porque explicitam grandes diferenças entre coisas tradicionalmente classificadas sob o rótulo geral de premissas. De fato, a lógica clássica considera como premissa maior aquilo que o autor chama de Suporte e Justificativa, e de premissa menor o que ele denomina Dado. 0 modelo de Toulmin traduz muito adequadamente o movimento do discurso argumentativo em linguagem ordinária, já que não se constitui como um modelo rígido, mecânico, causal, do tipo se $x$, então y, característico da demonstração. A introdução do Modalizador e da Refutação permite extrair de Dados não qualificados uma Conclusão que o seja, diferentemente do que acontece no silogismo tradicional.

Os seis componentes do argumento de Toulmin (2001) estão identificados e são objeto de atividades específicas no material da Olimpíada. Entretanto, para a nossa análise dos textos, interessa destacar três pontos importantes. 0 primeiro é o de que a Conclusão, ou seja, a tese a ser defendida, é sempre uma afirmação de natureza controvertida. Nas oficinas, assim como no jogo QP Brasil, há atividades cujo objetivo é levar o estudante a avaliar a natureza do que se denomina ali questão polêmica (CENPEC, 2010). Como veremos adiante, definir e recortar com precisão a polêmica a ser focalizada no artigo de opinião foi um passo crucial para o sucesso da argumentação. 
O segundo ponto a ser destacado é o de que o modelo de Toulmin (2001) pode ser aplicado tanto a cada sequência argumentativa que compõe o discurso argumentativo quanto ao texto como um todo, já que é possível estabelecer uma recursividade (GARCIA, 1984) entre os componentes do argumento, de modo que uma Conclusão possa gerar um novo Dado, que servirá de argumento para uma nova Conclusão, e assim por diante. Definese, assim, a possibilidade de se estabelecer diferentes níveis de argumentos (GARCIA, 1984) no interior de um mesmo texto, sendo que cada nível funciona como uma aproximação gradual, realizada passo a passo, do argumento de nível superior, - a tese final - que comporá a estrutura geral ou plano global dos textos que veiculam discursos argumentativos. Tal estrutura realizase, em geral, na clássica estrutura tripartida introdução - desenvolvimento - conclusão, não por acaso correspondente aos três elementos do núcleo da argumentação, dado - justificativa - conclusão. Desempenham papel fundamental nessa construção os articuladores textuais, elementos linguístico-gramaticais (tais como em primeiro lugar, finalmente, em seguida, assim, desta forma, de outro ponto de vista, entretanto, etc.) cuja função é a de estabelecer e deixar evidente as relações entre partes do texto, parágrafos e períodos, sinalizando para o leitor a direção argumentativa do raciocínio, estabelecendo a coesão no texto, assegurando o fio do discurso. Tanto a efetivação do plano global tripartido quanto a utilização dos articuladores textuais, nos artigos de opinião, foram objeto de oficinas específicas, no material, e serão objeto de exame na análise da amostra.

O terceiro ponto a ser destacado diz respeito ao uso, no texto, da refutação que, por sua vez, está relacionado à necessidade de reconhecer as características do auditório para antecipar e rebater possíveis argumentos contrários. Exercer tal movimento supõe “colocar-se na pele de um outro", exercitando a alteridade. Foi justamente com a intenção de proporcionar ao aluno esse tipo de exercício que o jogo QP: Brasil previu a necessidade de, em algumas jogadas definidas pela sorte, o estudante ter que defender uma posição com a qual ele não concorde, obrigando-o a avaliar argumentos previamente fornecidos como contrários ou favoráveis à determinada tese e/ ou a buscar argumentos próprios para convencer os jurados (o auditório) para vencer a rodada. Em um vídeo produzido para a divulgação desse material junto às escolas, em que é possível assistir a alguns estudantes jogando, fica patente o esforço que os adolescentes têm que realizar para conceber vozes discordantes das suas, formular como próprias posições de terceiros e expressá-las oralmente, visando provocar uma impressão positiva sobre os jurados. Segundo depoimentos de alunos realizados no próprio vídeo, a 
necessidade de realizar tal movimento foi fundamental para, muitas vezes, levá-los a reavaliar a própria posição quanto à questão polêmica proposta, fosse para alterá-la ou reforçá-la. Entretanto, como se verá adiante na análise, a utilização da refutação nos textos, além de ser ainda bastante escassa, nem sempre é feita de forma eficaz.

Finalmente, ainda considerando a necessidade de definir estratégias e mecanismos argumentativos para obter a adesão do auditório, há de se considerar, dentre os diferentes tipos de argumentos, quais seriam os mais adequados e eficazes à situação de comunicação, ao tema focalizado na argumentação e ao efeito de sentido que se quer produzir sobre os destinatários. Para tratar dessa distinção entre tipos de argumentos, o material da Olimpíada utilizou o trabalho de Rieke e Sillars (1975), autores que, partindo do modelo proposto por Toulmin (2001), distinguem seis tipos de argumentos, considerando as diferentes relações lógicas existentes entre dados, justificativas e conclusões. Tal tipologia permite avaliar e eleger com maior precisão que tipo(s) de argumento(s) pode(m) funcionar melhor no contexto do debate a ser travado no interior do texto a ser produzido. Vejamos os seis tipos de argumentos definidos por Rieke e Sillars (1975):

1. Argumento de princípio: é aquele que se aproxima da forma mais pura de dedução, em que a justificativa é um princípio geral e a legitimidade da conclusão é praticamente automática.

2. Argumento por generalização: é o mais próximo da indução; apresenta um ou mais exemplos suficientemente significativos que conduzem a um princípio geral, a conclusão.

3. Argumento por causa: em que o movimento de argumentação tanto pode se dar no sentido causa efeito, como no sentido efeito causa.

4. Argumento por sinal (ou evidência): baseia-se numa justificativa que se constitui numa evidência suficiente para validar a conclusão.

5. Argumento por analogia: valida a conclusão através de uma comparação entre duas situações que possuem características semelhantes.

6. Argumento de autoridade: em que a conclusão justifica-se porque é sustentada por uma pessoa confiável.

A esse respeito cabe destacar o seguinte: se, quando considerado o plano global do texto, são os articuladores textuais que garantem o fio do discurso, 
já na formulação de cada argumento que comporá a argumentação do texto como um todo, são os operadores argumentativos, - elementos lingüísticogramaticais tais como pois, já que, então, portanto, consequentemente, dado que etc. - que assumem papel fundamental, pois expressam a relação lógica que se efetua entre dados, justificativa e conclusão.

Da mesma forma que anteriormente, tanto a tipologia de argumentos, devidamente exemplificada para os estudantes, quanto a adequada escolha do operador argumentativo foram objeto de atividades nas oficinas e, nesse caso, particularmente no jogo QP Brasil, já que além do jogo supracitado que previa a argumentação dos estudantes para convencer os jurados havia, no inverso do tabuleiro que servia de base ao primeiro jogo, uma outra possibilidade de jogar com o material; essa segunda previa um sistema de pontuação para jogadores que conseguissem classificar corretamente, segundo a tipologia de Rieke e Sillars (1975), 144 diferentes argumentos, relacionados às 12 questões polêmicas que movimentam o primeiro tipo de jogo.

Definido o quadro teórico que deu sustentação ao conjunto de atividades que precederam a produção da versão final do artigo de opinião, passemos agora aos textos da amostra, buscando focalizar as estratégias argumentativas em jogo. Buscaremos tanto apontar as características mais gerais e recorrentes da amostra, como pinçar mecanismos discursivos, textuais e linguísticogramaticais utilizados para conduzir a argumentação em textos isolados, eleitos como representativos da amostra como um todo e que ilustram adequadamente o aspecto em foco. 0 exame incidirá sobre dois exemplares da amostra, não só em função do espaço de que dispomos, mas principalmente porque, dada a concepção de argumentação assumida, não seria possível trabalhar com trechos produzidos pelos alunos-autores, mas apenas com textos na íntegra.

\section{OS ARTIGOS DE OPINIÃO DA AMOSTRA}

Como foi apontado em Garcia (2010; 2011), uma visão geral sobre os textos da amostra revela, antes de mais nada, que esses jovens brasileiros têm posição própria em relação a questões de natureza social e entendem perfeitamente que o artigo de opinião é um gênero adequado para divulgá-la. Em geral, os textos estão relativamente bem estruturados, vêm assentados em informações que demandaram pesquisa e revelam consistência. É digno de nota o fato de que tanto os assuntos que os alunos elegeram quanto 0 grau de envolvimento pessoal que os textos revelam ao tratá-los indicam que a escolha desse gênero para a faixa etária foi acertada. Em outras palavras, 
nota-se claramente que os alunos gostam de opinar - e por escrito. Portanto, dão mostras de interesse pelo debate e de apreço à argumentação.

No entanto, o reconhecimento das condições de produção e o domínio das regras do jogo argumentativo, no artigo de opinião, ainda não se mostram firmemente estabelecidos.

Pode-se dizer que a característica mais recorrente na amostra - presente em torno de $70 \%$ dos textos - é a de que a polêmica de fundo não está adequadamente formulada ou claramente colocada, o que não favorece que a opinião se fundamente em argumentos, no contexto de um debate. Para entender o que se quer dizer com isso é preciso relembrar que, para Toulmin (2001), a conclusão (ou tese) que se quer defender ao se argumentar deve ser de natureza controvertida, o que raramente realizou-se de forma satisfatória nos textos analisados.

Para refletirmos sobre esse traço tão marcante da amostra é preciso considerar que há diferença entre, de um lado, eleger um tema amplo, potencialmente polêmico e, de outro, definir uma das diversas faces de uma polêmica. Vejamos alguns exemplos retirados dos próprios textos: a presença de uma empresa poluidora na cidade, a ausência de oportunidades de trabalho na região, uma nova medida que proíba os bares de permanecerem abertos na madrugada, o abuso sexual de crianças e jovens, a segurança e a violência nos grandes centros urbanos são todos temas de natureza social, de interesse público, cuja discussão afeta o coletivo. Mas, assim formulados, ainda não são controversos. A polêmica se instala quando pelo menos duas posições opostas sobre um determinado aspecto do tema se confrontam. Considerando os temas acima, teria sido necessário especificá-los para transformá-los em polêmicas: vale a pena assumir o ônus da poluição na cidade para obter mais desenvolvimento? as medidas tomadas pelas autoridades locais estão sendo eficazes para gerar empregos na região? o fechamento dos bares na madrugada diminui o risco de violência para os cidadãos? crianças e jovens vítimas de abuso sexual devem ser obrigados a depor contra os criminosos na polícia? o aumento da violência nos grandes centros urbanos é uma consequência direta das enormes desigualdades sociais que existem na região?

Como se vê, teria sido preciso primeiro fazer o recorte de um aspecto do tema (já que outros aspectos do mesmo tema também poderiam ser transformados em polêmica), para depois enunciar a controvérsia, geralmente expressa na forma de uma pergunta cuja resposta só possa ser sim ou não. Vejamos um exemplo que ilustra o que se está dizendo: 


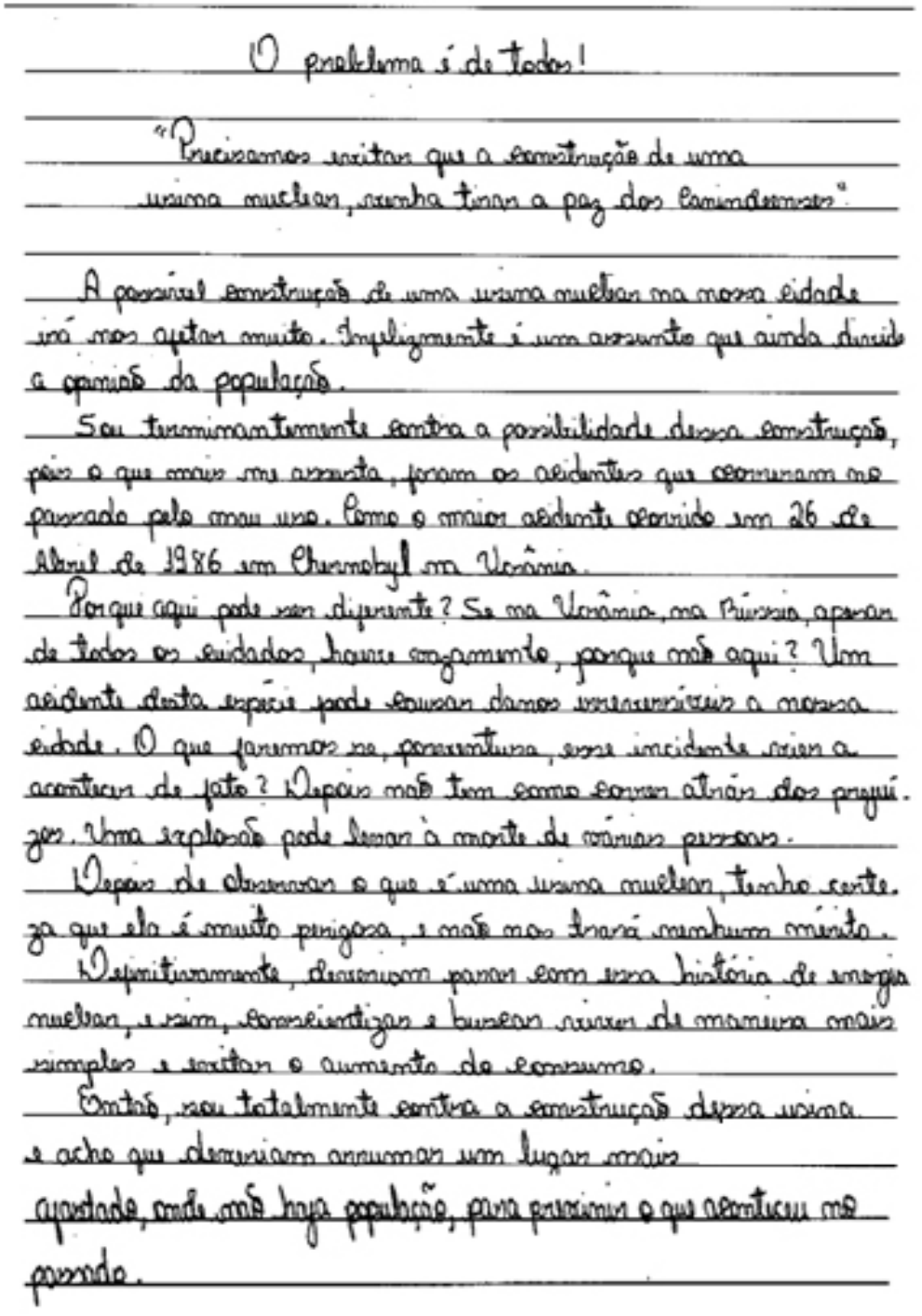

\section{D.O.S., aluna-autora}

Embora seja possível deduzir muito do que está apenas sugerido nesse texto, para circunscrever de fato uma polêmica caberia, antes de enunciar uma posição sobre ela, uma breve explanação sobre o que é uma usina nuclear, suas vantagens e desvantagens, seguida da formulação expressa da polêmica que, nesse caso, poderia ser a seguinte pergunta retórica: vale a pena correr os riscos de se ter uma usina nuclear na região para desfrutar das vantagens que isso traria?

Mas nossa aluna-autora já na 3a linha do texto declara sua posição (que, aliás, já estava posta no subtítulo): "Sou terminantemente contra a possibilidade dessa construção", alegando o que chama de "mau uso". Nessa passagem, ela não só não explica o que entende por “mau uso" como deixa muitas etapas do 
argumento por causa e consequência implícitas, para o leitor inferir; assim como não assinala a relação entre dados, justificativa e conclusão por meio do operador lógico. Veja-se: "sou contra a construção da usina nuclear (pois) o mau uso (pode provocar um desastre)". É sobre esse "mau uso" ainda não adequadamente explicado que se constrói o outro argumento, desta vez, por comparação (assim como houve desastre em Chernobyl, também pode haver aqui).

Formulados como estão, os argumentos seriam facilmente questionados por um oponente. Entretanto, se ela tivesse ido buscar sustentação em outros fatos, dados ou se introduzisse argumentos intermediários que contribuíssem para a tese final, teria sido convincente. Por exemplo, não seria difícil introduzir aqui argumentos de autoridade (segundo Fulano, um especialista em energia nuclear....), ou então ter utilizado argumentos de princípio (para que a humanidade sobreviva, é preciso evitar o que pode vir a contaminar irremediavelmente o meio ambiente). De fato, considerando-se o tema espinhoso, o número de argumentos utilizados é bastante reduzido.

Esta última observação serve para ilustrar outra característica da amostra: os argumentos postos em jogo poderiam ser repensados quanto à quantidade e qualidade. 0 padrão, na amostra, ficou em torno de dois argumentos por texto, variando entre três tipos dentre os seis propostos por Rieke e Sillars (1975). Os argumentos por causa e consequência, por exemplificação e por evidência foram os mais utilizados. Mais raros foram os argumentos de autoridade (que dependem de pesquisa e domínio do tema), por comparação (que também demandam a busca de casos similares) e por princípio (assentados em leis, regras e preceitos gerais).

Do ponto de vista discursivo, nos termos de Perelman (1987), a impressão que se tem é que o Texto 1 impõe um ponto de vista, exprimindo mera relação de força, sem buscar a adesão intelectual do auditório. Para fazê-lo, teria sido necessário prever suas reações e adaptar o discurso a estas reações. Não há aqui a consideração adequada e suficiente dos contra-argumentos, favoráveis à construção da usina nuclear; este ponto de vista poderia ter sido expressamente formulado e devidamente rebatido, movimento argumentativo que, no modelo de Toulmin (2001), seria realizado por meio da refutação. A título de exemplo, nossa aluna-autora poderia ter formulado o contra-argumento de que a energia nuclear é tida como mais limpa do que as demais formas de obter energia, para rebatê-lo em seguida ou aceitá-lo em parte. Tal movimento exigiria inclusive que, ao defender a sua tese, a autora se mostrasse um pouco menos radical, e utilizasse recursos para modalizar 
(TOULMIN, 2001) suas afirmações, o que inexiste no texto: a questão é tratada sempre em termos absolutos.

Parece ser possível dizer, portanto, que ao tentar persuadir seu auditório boa parte dos alunos-autores acaba por cometer dois erros que tornam a argumentação ineficaz: primeiro, supor como suficientemente compreendida pelo leitor a polêmica de fundo e, segundo, incorrer em petição de princípio, ou seja, supor como aceita a tese que teria que ser defendida.

O efeito causado por estes traços é o de gerar textos que ainda não se configuram de fato como artigos de opinião típicos. Na verdade, parecem mais buscar realizar uma denúncia, desvelar uma ação ou fato demeritórios que permaneciam escondidos, do que analisar ou refletir sobre um tema controverso, analisando as suas várias faces. É verdade que eles se assemelham a textos opinativos que circulam em jornais, revistas e na mídia eletrônica, textos em que há posições claramente assumidas, mas que ainda não são artigos de opinião típicos.

O que ocorre no Texto 1 e em boa parte da amostra é que os autores posicionamse claramente a favor de um dos lados da polêmica, expressando a sua opinião, mas não em relação à natureza do problema em foco, e sim em relação ao que deveria ser feito para solucioná-lo. Nesse sentido, é possível dizer que formulações como "deve-se fazer x" predominaram sobre formulações do tipo “x acontece porque $y$ ”, mais esperadas em gêneros argumentativos. Para concluir o raciocínio, realiza-se quase sempre uma espécie de conclamação para que as autoridades, o governo, os responsáveis, alguém, enfim, tome providências, proponha uma medida, resolva a situação, acabe com 0 problema, mude de comportamento, propondo, muitas vezes, uma solução genérica e quase utópica. (GARCIA, 2011).

Como estas são características bastante recorrentes na amostra, vale a pena nos determos para entender as razões que poderiam explicá-las.

Cabe considerar que, mesmo que o professor tenha conseguido realizar adequadamente as atividades propostas no material das Olimpíadas para preparar o estudante a escrever - o que não é possível garantir, por vários e diversos motivos -, os alunos-autores ainda assim precisariam ter sido especificamente preparados para gerenciar mais adequadamente as condições de produção que se colocam nesse certame, o que também os levaria a refinar os mecanismos e estratégias argumentativas a serem utilizados no texto.

Um primeiro problema a ser enfrentado pelos estudantes na definição da polêmica a ser debatida era atender ao tema geral da Olimpíada (O lugar em 
que vivo) e, simultaneamente, eleger uma questão que dissesse respeito ao coletivo, de interesse público. Por essa razão, as próprias oficinas apontavam para a necessidade de o texto realizar uma articulação entre os aspectos locais e questões de natureza mais geral, nacional ou internacional. Nem sempre os textos da amostra obtiveram sucesso nessa articulação. Em vários deles, mais voltados para a denúncia de uma situação local, o aluno-autor fixouse em uma situação particular, sem estender a validade de suas reflexões para aspectos mais gerais, sem mostrar como o problema focalizado era, na verdade, a expressão de um fenômeno social mais amplo. Por outro lado, ocorreu bastante também a dificuldade inversa: o tratamento de um problema mais amplo - como educação, poluição, comportamento etc. - sem que a discussão tenha sido trazida para o aspecto local, seja pela utilização de um exemplo na região, seja para tomar uma situação ocorrida na cidade como ponto de partida das reflexões.

Outro aspecto determinante das condições de produção do artigo de opinião no concurso é o das várias instâncias para as quais o estudante se dirige ao escrever. A esse respeito Rangel (2011) aponta que, na Olimpíada, qualquer que seja o gênero em foco, o aluno escreve para pelo menos três instâncias distintas:

\section{(...) A mais imediata delas é sua própria escola: o(a) professor(a), os colegas de turma; eventualmente, toda a comunidade escolar. Mas, como as oficinas o fazem viver um determinado gênero, ele escreve também "para a vida", ou seja, para as situações sociais a que esse gênero está associado. Assim, a circulação de um ou outro texto pode, até, ir além dos muros escolares. Finalmente, considerando-se o contexto do concurso, nosso aluno escreve para ser reconhecido em suas potencialidades - para competir, mesmo que estar entre os finalistas pareça, a princípio, uma meta muito longínqua. (RANGEL, 2011, p.62)}

Como vimos com Perelman (1987), um dos grandes problemas colocados à frente do orador é descobrir quem de fato são os seus destinatários, movimento imprescindível para o processo de adaptação e construção da argumentação. Ora, temos que convir que encontrar formas de descobrir o que pensa o auditório no contexto desse concurso é tarefa que requer consideráveis esforços, especialmente para adolescentes desejosos de firmar um ponto de vista próprio.

Um segundo tópico a ser considerado é o de que o artigo de opinião, um gênero que circula na esfera jornalística, é geralmente produzido por jornalistas experientes e, muitas vezes, especializados nos temas que debatem. Já os nossos jovens autores nem sempre dominam o assunto que escolhem focalizar e, embora o material da Olimpíada insista nessa necessidade, nem sempre as condições escolares para a pesquisa são favoráveis.

Seria necessário, portanto, para resolver em parte o primeiro ponto, que o professor pudesse (re)construir com os estudantes as características do cadernoscenpec | São Paulo|v.2 | n.1| p.99-120 | julho $2012 \quad 113$ 
auditório, levando em conta a polêmica em jogo, na tentativa de ajudar o aluno a construir uma representação dos destinatários do concurso, assim como dos opositores à sua tese. Para minimizar os efeitos do segundo ponto, caberia ainda ao professor programar e orientar atividades de alimentação temática que levassem os estudantes a se aprofundarem um pouco mais nos temas que vão debater.

Vejamos o que ocorre no Texto 2 para tratar um pouco mais do primeiro ponto, assim como de outros aspectos da argumentação a serem ainda examinados.

TEXTO 2

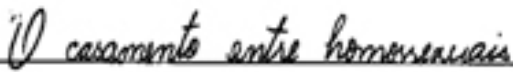

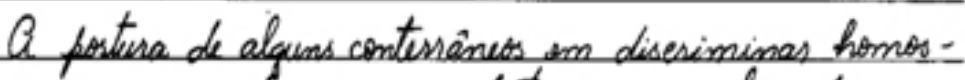
savais tim me indupade e me pits persas sobre ate que

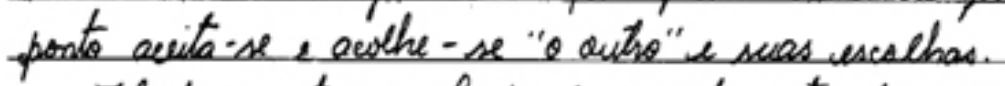

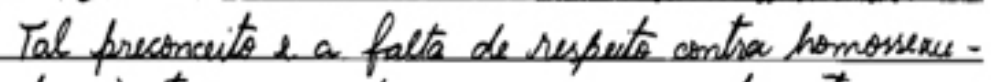

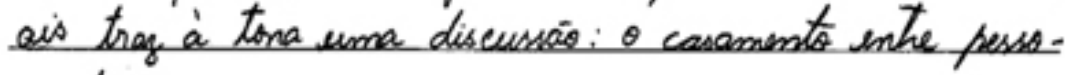
as de mesmo sexo.

Pera alqumas persess, o homonsexual nais i fitho de sleus 2 o casamente ente pessos do mesmo sxo $i$ ces:sa do deminis Viäo essa, que pretende coilis o livere as. bitris de amar es ser amado.

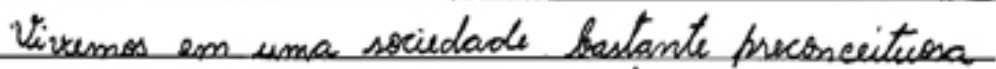

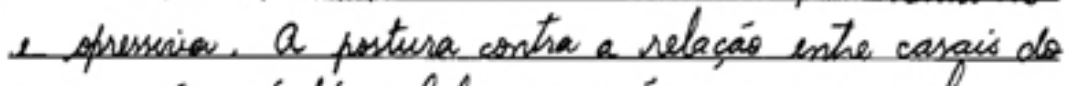

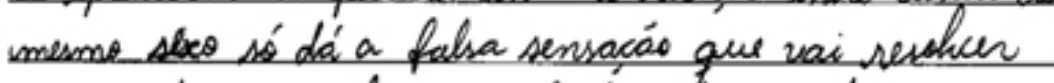
su mudar un homonerual tramptormando.o em

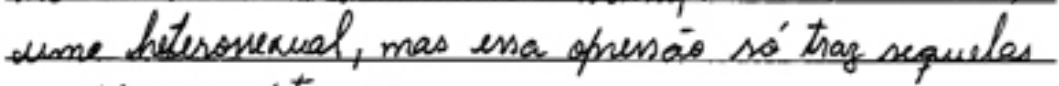
2 pirsor a situogás. Leefendo uma socidade que despa a felicidadere

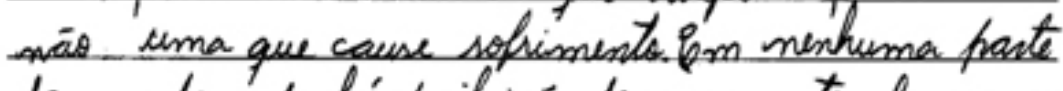
do munde onde há proibisiśs do casamento homosse. mal mudau a opéas sexual de uma penoa. a

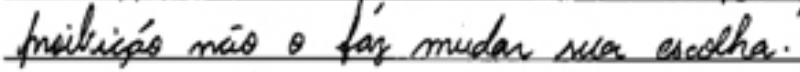

Soer a fores do caraments perque de acosds com a

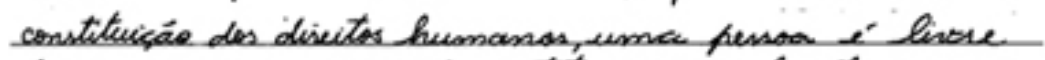
hara vires, cesar is e constitua uma fametia. 


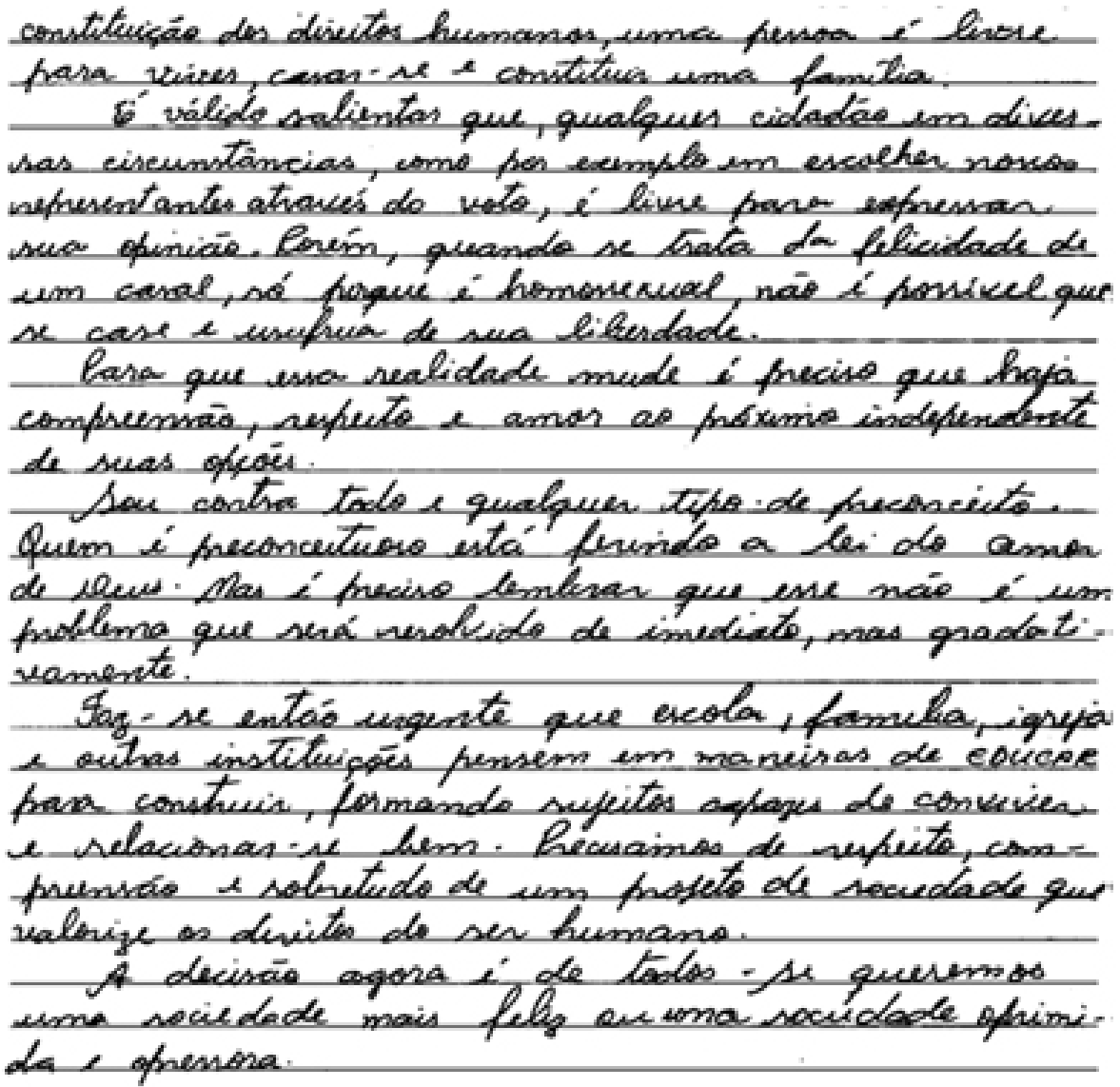

\section{A.S.A., aluno-autor}

Embora mais articulado e próximo de um artigo de opinião do que o anterior, ainda assim, este que acabamos de ler também apresenta características semelhantes às do Texto 1: a questão polêmica não está claramente expressa, as vozes discordantes são vagas e genericamente aludidas, não há refutação eficaz das posições contrárias às que o texto defende. Da mesma forma que o anterior, não se pode considerar que o Texto 2, do ponto de vista discursivo, levará um auditório minimamente resistente a aderir à sua tese.

Para que isto pudesse ocorrer, teria sido necessário que o professor (ou mesmo outro leitor experiente) ajudasse o aluno-autor a resgatar o auditório por meio de perguntas como: Qual é exatamente a pergunta sobre a qual há discordâncias e que você busca responder com seu texto? Que outros fatores entram em jogo quando se trata de dar uma opinião que envolve a sexualidade das pessoas? Quem debate com você? O que pensam seus opositores? Quem são eles? Que outras razões alegam aqueles que são contra o casamento entre homossexuais? Que valores buscam preservar? Como é possível apontar fragilidades em suas posições, refutá-los? Que outros argumentos são usados por pessoas que pensam como você? Também 
perguntas que ajudassem o aluno a gerenciar o que chamamos de condições de produção do próprio concurso talvez pudessem ter gerado um texto que atendesse mais satisfatoriamente às demandas do tema geral. Como tratar deste assunto no contexto de um concurso cujo tema é 'O lugar onde vivo'? Como trazer a questão para o cotidiano da nossa cidade? Que fatos podem ser citados? É possível mencionar um evento local de onde você pudesse partir?

Sem dúvida, buscar responder perguntas semelhantes a essas levaria 0 estudante a repensar formulações, encaminhamentos, pontos de partida e de chegada, estratégias e mecanismos argumentativos que seriam aplicados ao texto nas diferentes "etapas envolvidas no processo de escrita: o planejamento, a escrita da primeira versão, a leitura crítica - pelo próprio aluno, pelos colegas, pelo professor - a(s) reescrita(s) e, finalmente, a revisão." (RANGEL, 2011, p. 69).

Além do aspecto discursivo apontado, o Texto 2 ainda não atende satisfatoriamente a outro aspecto textual próprio da argumentação e do gênero: note-se como não é possível distinguir claramente, no plano global, a estrutura tripartida introdução - desenvolvimento - conclusão que tende a expressar, nos termos de Toulmin (2001), os três elementos do núcleo da argumentação dado - justificativa - conclusão. O raciocínio salta de um plano a outro e volta ao anterior, sem que se configure uma clara progressão argumentativa, construída por meio da apresentação de argumentos de nível intermediário que contribuíssem, passo a passo, para a construção do argumento de nível superior que, por sua vez, apresentaria a tese final do texto.

Essa falha reflete-se na paragrafação do texto, para a qual não se depreende claramente um critério. Em muitos momentos o aluno-autor parece mudar de parágrafo ao dar início a um novo período. Assim, a paragrafação não é usada como um recurso gráfico para produzir sentido, para indicar ao leitor que o texto vai mudar de direção, passar a outro momento, apresentar outra perspectiva, alterar seu movimento. Logo, a falha em delimitar claramente, no plano global do texto, a estrutura tripartida própria da argumentação não permite ao aluno-autor definir critérios pertinentes para a paragrafação.

Quanto ao aspecto linguístico-gramatical, chama a atenção o fato de que as partes do texto, os parágrafos, períodos e orações não aparecem suficientemente conectados, o que compromete a sua coesão. 0 texto carece de articuladores textuais, que deveriam aparecer estabelecendo relações entre as suas partes, e de operadores argumentativos que expressassem a relação lógica entre dados, justificativa e conclusão nos argumentos de nível 
intermediário e superior. No texto todo, só aparecem dois conectivos (mas e porém); este último, duas vezes. Ou seja, apenas três ideias relacionadas por conectores, ainda assim, internamente ao parágrafo.

Assim como ocorreu com o aspecto discursivo nos dois textos analisados, os aspectos textual e linguístico-gramatical examinados no Texto 2 ilustram traços que foram recorrentes na amostra como um todo, o que indica que ambos também merecem ser trabalhados de forma mais sistemática e regular pelo professor ao utilizar o material da Olimpíada.

\section{À GUISA DE CONCLUSÃO}

As análises realizadas na seção anterior não devem dar a falsa impressão ao leitor de que os jovens estudantes brasileiros que concorreram na Olimpíada 2010 não conseguem defender pontos de vista próprios sobre temas que interessam à coletividade. Ao contrário, na grande maioria dos textos, eles se revelaram capazes de identificar e de se preocupar com questões sociais; tiveram o que dizer acerca delas, levaram em conta o coletivo, quiseram e gostaram de opinar. Portanto, mesmo não se classificando entre os finalistas da Olimpíada em 2010, venceram desafios importantes, e isto certamente revela também o empenho de seus professores.

0 que se procurou apontar neste artigo foram as características mais salientes relativas ao modo como a argumentação foi conduzida nos textos; e os resultados nos permitem concluir que eles se situam, por assim dizer, no limiar da persuasão: ainda não se constituem como artigos de opinião típicos, pelas razões apontadas, mas seus autores já dão mostras de terem iniciado um processo de apropriação desse gênero do discurso, cujo objetivo final é convencer um auditório, pela argumentação, de que uma certa opinião deve ser aceita como válida, ou seja, obter ou intensificar a adesão dos leitores a uma certa tese, por meio da linguagem escrita. Como se viu pelo viés dos autores visitados, trata-se de um movimento complexo de ser realizado, seja na fala ou na escrita, e que requer, portanto, a prática constante e bem orientada.

Outros aspectos discursivos, textuais e linguístico-gramaticais dos textos da amostra - tais como a ancoragem e o gerenciamento de vozes no texto, a seleção de palavras, do registro e das variedades linguísticas, os mecanismos para garantir a coesão e a coerência do texto, a definição dos títulos, o atendimento às convenções da escrita etc. - também concorrem para 
construir a argumentação; entretanto, embora merecessem ser examinados, não chegaram a sê-lo neste artigo, por uma questão de espaço.

Para orientar o estudante a evitar as falhas na argumentação apontadas aqui, uma boa estratégia a ser utilizada em sala de aula seria a de selecionar alguns artigos de opinião produzidos pelos alunos, na sua primeira versão, e propor à turma o desafio de formular, por escrito, a polêmica que está por trás de cada um, na forma de uma pergunta a ser respondida com um sim ou um não. Em seguida, promover debates abertos sobre as polêmicas formuladas, pedindo antes que os alunos pesquisem e registrem por escrito as posições contrárias e as favoráveis às polêmicas e que arrolem os argumentos que seriam usados para defender as duas diferentes posições, independentemente da posição que eles já possam ter sobre o tema. A prática do debate oral pode levar os estudantes a realizar movimentos importantes para reescrever o próprio texto: formular expressamente polêmicas, avaliar os argumentos utilizados pelos oponentes, assim como os seus próprios, identificando aqueles que são fracos, duvidosos, raciocínios falsos e pressupostos questionáveis.

Esse exercício certamente favorecerá que o aluno perceba mais claramente que esse gênero do discurso não opera pela simples formulação de opiniões, mas pela fundamentação e negociação de posições, procedimentos que, como apontamos, mostrou-se bastante tímido, na grande maioria dos textos da amostra. 


\section{On the threshold of persuasion: argumentative movement in the writing of opinion pieces by Brazilian students}

\section{ABSTRACT}

This paper introduces some of the results from a study related to 383 texts, produced as opinion pieces by 2nd and 3rd year Secondary School students within the context of the 2010 Olympics. Based on a argumentative conception that is both discursive (PERELMAN, 1987) as well as structural or "anatomical" (TOULMIN, 2001; RIEKE; SILLARS, 1975) and using the aforementioned sample as the object of study, the investigation sought to understand how argumentative mechanisms and strategies are put to work in texts, from a discursive, textual and linguistic-grammatical point of view. The difficulty in reconstructing the features of the auditorium to represent those at whom the discourse is aimed, which also resulted from the complex text production conditions, is found to be a determinant to explaining the large number of sample examples that did not meet the criteria of a typical opinion piece.

KEYWORDS: Argumentative strategies. Written text production. Opinion piece. 


\section{REFERÊNCIAS}

CENPEC. Pontos de vista. Caderno do professor: orientações para produção de textos. Equipe de produção: Egon de Oliveira Rangel, Eliana Gagliardi e Heloísa Amaral. São Paulo: Cenpec, 2010. Coleção da Olimpíada.

CENPEC. Questões Polêmicas do Brasil: o jogo da argumentação. São Paulo: Cenpec, 2008. Coleção da Olimpíada.

GARCIA, Ana Luiza Marcondes. Argumento e redação escolar. Dissertação (Mestrado em linguística) - Instituto de Estudos da Linguagem, Universidade Estadual de Campinas, Campinas, 1984.

GARCIA, Ana Luiza Marcondes. 0 que dizem os artigos de opinião semifinalistas de 2010. Na Ponta do Lápis, São Paulo, n. 15, p. 14-19, 2010.

GARCIA, Ana Luiza Marcondes. Retratos da amostra: os dois lados da moeda. In: RANGEL, Egon de Oliveira (Org.). 0 que nos dizem os textos dos alunos? São Paulo: Cenpec, 2011. p. 48-59.

PERELMAN, Chaïm. Argumentação. In: ROMANO, Ruggiero (Org). Oral/escrito: Argumentação. Lisboa: Imprensa Nacional/ Casa da Moeda, 1987. p. 234265. (Enciclopédia Einaudi, v. 11)

PERELMAN, Chaïm; OLBRECHTS-TYTECA, Lucie. Tratado da argumentação: a nova retórica. São Paulo: Martins Fontes, 2000.

RANGEL, Egon de Oliveira. Caminhos da escrita. In: RANGEL, Egon de Oliveira. (Org). O que nos dizem os textos dos alunos? São Paulo: Cenpec, 2011. p. 60-71.

RIEKE, Richard; SILLARS, Malcolm Osgood. Argumentation and the decision making process. Illinois: Scott, Foresman and Company, 1975.

TOULMIN, Stephen. Usos do argumento. São Paulo: Martins Fontes, 2001. (Ferramentas) 